\title{
Refugees and migrants struggle to obtain health care in Europe
}

I $\mathrm{t}$ seems Canada is not alone in limiting hospital, physician and other medical services provided to refugee claimants.

The recent restriction on services to those that are "of an urgent or essential nature" (www.cmaj.ca/lookup/doi/10 .1503/cmaj.109-4203), which included a prohibition on the provision of health care to rejected refugee claimants and people from nations on a Designated Countries of Origin list (predominantly European nations that "do not normally produce refugees") unless there is a public health threat (www.gazette.gc .ca/rp-pr/p2/2012/2012-04-25/html/si-tr 26-eng.html) is viewed as "inhumane" by a cadre of Canadian physicians (www.cmaj.ca/lookup/doi/10.1503/cmaj .109-4208).
But if a new report from Médecins du monde - Doctors of the World in Europe is any indication, it also appears to becoming a norm in many developed nations.

Undocumented migrants, asylum seekers and other vulnerable populations are finding it increasingly difficult to obtain health care in Europe for reasons ranging from government policies to an inability to pay $100 \%$ of the costs, according to the report, Access to Health Care for Vulnerable Groups in the European Union in 2012: An Overview of the Condition of Persons Excluded from Healthcare Systems in the EU (www.epim.info /wp-content/uploads/2012/04/Medecins -du-Monde-EU-advocay-paper-on-access -to-healthcare..pdf).
"The European Union [EU] needs to ensure full health coverage to people who are already confronted with numerous vulnerability factors," states the report, which was based on interviews with 4838 undocumented migrants, asylum seekers, EU nationals who had lost their residency status and other disadvantaged peoples in five European cities (Amsterdam, Netherlands; Brussels, Belgium; London, England; Munich, Germany and Nice, France).

"The implementation of exclusion measures that target undocumented migrants, the Roma, drug users, the homeless, and sex workers has increased the likelihood that their health will deteriorate. In the European Union, financial barriers to healthcare, acts of discrimination, and frequent police harassment

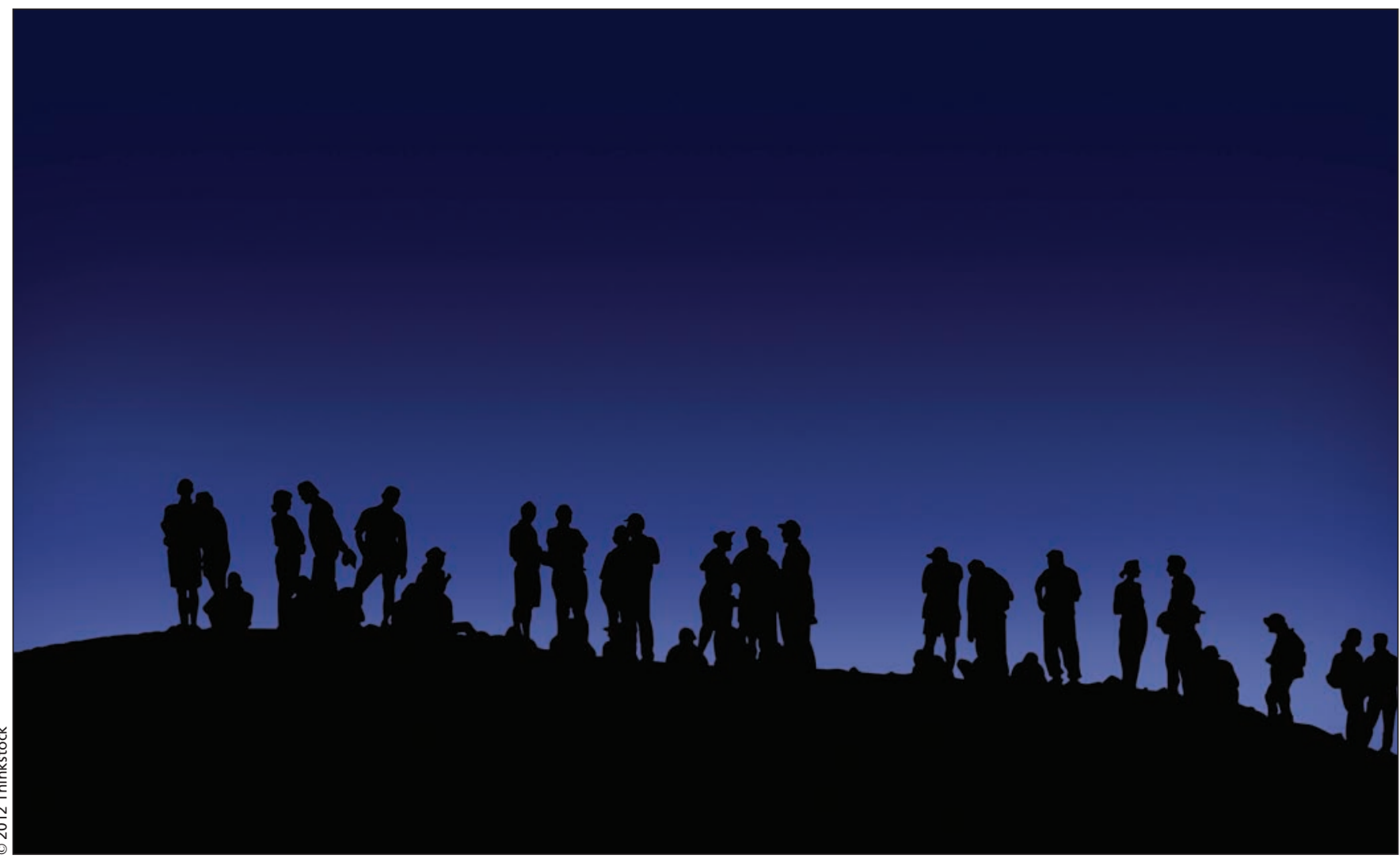

The European Union Agency for Fundamental Rights says that among the barriers to health care for refugees and undocumented migrants on the continent is "fear of detection due to information passed on to the police." 
combined with the fear of being reported to the authorities and subsequently deported are leading an increasingly greater number of people to feel it is unsafe for them to seek medical attention. Consequently, they do not obtain primary health care, have no access to prevention programmes, or to treatment for chronic diseases; and this is true for children, pregnant women and adults in general."

The report also asserts that roughly one-quarter of the vulnerable population groups were essentially denied access to health care.

The conclusions are clear cut, Dr. Bernd Rechel, senior researcher at the European Observatory on Health Systems and Policies in the London School of Hygiene and Tropical Medicine writes in an email. "These findings indicate a clear failure of European health systems. All European countries have signed up to international legal instruments that guarantee the basic human right to health. Yet, many of them have established legal or administrative obstacles that prevent undocumented migrants or asylum seekers from accessing health services. There is an urgent need to improve accessibility of health services for vulnerable groups,"

The impediments to access include "laws and regulations, lack of knowledge of the rights (on the part of patients and health professionals), lack of financial resources and language barriers," Nathalie Simmonot, deputy director of domestic programs, communication and advocacy for Médecins du Monde/Doctors of the World International Network, writes in an email.

The access to health care provided to asylum seekers and undocumented migrants appears to vary substantially across European Union nations.

Migrants have very uneven access to primary care and medications as a result of both "law and practice" in Europe, according to a study conducted by the European Union Agency for Fundamental Rights (http://fra.europa.eu/fraWeb site/attachments/FRA-2011-fundamental -rights-for-irregular-migrants-healthcare _EN.pdf). The five main barriers were "costs of care and complex reimbursement procedures; unawareness of entitlements by health providers and beneficiaries; fear of detection due to information passed on to the police; discretionary power of public and healthcare authorities; and quality and continuity of care."

Moreover, the report added, "there is often a disconnect between national legislation and what happens in practice."

Sweden is among the most difficult nations for undocumented migrants and asylum seekers to obtain health care, Carolina Falk, director of Médecins du Monde Sweden, writes in an email. "Swedish law does not entitle undocumented migrants any healthcare except emergency services which they must pay full price for."

In April, ongoing financial woes prompted Spain to limit its once-generous health coverage for undocumented migrants to emergency, prenatal, natal, postnatal and child care, according to José-Manuel Freire, head of the Department of International Health at the National School of Public Health in Madrid. The legislation would also apply to refugee claimants, says Estrella Galán Perez, secretary general of the nonprofit organization, the Spanish Commission for Refugees.

Among other measures, the report calls for European nations to improve equity of access to health care services, provide free vaccinations in the interest of public health and develop mechanisms to protect diseased people from being deported to countries that lack the ability to deliver appropriate health care. - Tiago Villanueva Gutierrez Arruda Marques, MD, Lisbon, Portugal

CMAJ 2012. DOI:10.1503/cmaj.109-4214 